\title{
Development of Avian External Genitalia: Interspecific Differences and Sexual Differentiation of the Male and Female Phallus
}

\author{
Ana M. Herrera ${ }^{a}$ Patricia L.R. Brennan ${ }^{c}$ Martin J. Cohn ${ }^{a}$ b

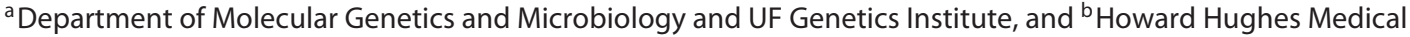 \\ Institute and Department of Biology, University of Florida, Gainesville, Fla., and ${ }^{\mathrm{C}}$ Graduate Program in Organismic \\ and Evolutionary Biology, Department of Psychology, University of Massachusetts, Amherst, Mass., USA
}

\section{Key Words}

Birds · Chicken · Clitoris development · Duck · Genital tubercle $\cdot$ Penis development $\cdot$ Phallus development

\begin{abstract}
Avian genitalia, particularly in waterfowl, are extremely diverse. Penis morphology varies among species, and penis length and elaboration are associated with the frequency of forced extra-pair copulations, yet the developmental mechanisms responsible for this variation are unknown. In addition, females have a small phallic structure that is homologous to the male phallus, but little is known about when or how sexual differentiation takes place. To determine whether species-specific genital morphologies and sexual differentiation occur during duck embryonic development, we characterized development from the onset of genital tubercle initiation through stages of sexual differentiation in 3 species. Pekin and Laysan ducks have long, thick penises, whereas those of Mandarin ducks are shorter and thinner. Development of the genital tubercle is similar throughout the pre-hatching period across the 3 species, suggesting that differences in penis morphology arise post-hatching. We observed that male and female phallus development is similar at early stages, but the female phallus later regresses. Then, we compared male and female genital development between ducks and chickens, which develop a non-intromit-
\end{abstract}

tent penis. We found that external genital development in male and female chickens resembles that of female ducks, which raises the possibility that male phallus development became feminized during galliform evolution.

(c) 2014 S. Karger AG, Base

Birds have the most variable genital morphology of any amniote group. This variation ranges from the largest penis for a given body size in any vertebrate $[\mathrm{McCracken}$ et al., 2001] to the complete absence of an intromittent penis in 97\% of all avian species [Briskie and Montgomerie, 1997; Brennan et al., 2008], yet there is no widely supported hypothesis to explain this pattern of variation [Brennan, 2013]. Even among the $3 \%$ of avian species that have a penis, the length, width, shape, surface elaboration, and coloration show wide variation [King, 1981; Briskie and Montgomerie, 1997]. Increased penis length and surface elaboration have been linked to high levels of promiscuity in waterfowl [Coker et al., 2002; Brennan et al., 2007]. This promiscuity results primarily from forced extra-pair copulations (FEPCs), which occur at high frequencies (up to $40 \%$ of all observed copulations) in some species of waterfowl but are rare in other birds [McKinney et al., 1983; Afton, 1985; McKinney and Evarts, 1998; Davis, 2002; Brennan and Prum, 2012]. In waterfowl, penis length and elaboration are correlated with the fre-

\section{KARGER 125}

C2014 S. Karger AG, Base

$1661-5425 / 14 / 0091-0043 \$ 39.50 / 0$

E-Mail karger@karger.com

www.karger.com/sxd
Martin J. Cohn

Department of Molecular Genetics and Microbiology and Department of Biology University of Florida, PO Box 103610

Gainesville, FL 32610 (USA)

E-Mail mjcohn@ufl.edu 
quency of FEPCs, so species with high levels of FEPCs have longer and more elaborate genitalia than species where FEPCs are uncommon [Coker et al., 2002; Brennan et al., 2007]. The developmental mechanisms responsible for this variation at species level are unknown.

In this study, we investigate external genital development in ducks to determine whether species-specific differences in penile size and structure are generated by modulation of embryonic development or, alternatively, whether these features arise after hatching. We examined embryonic development of the penis in 3 species of duck that have different reproductive strategies and penile morphologies. Mandarin ducks (Aix galericulata) are monogamous and form pair bonds that can last for several seasons [Dilger and Johnsgard, 1959]. Only one instance of female coercion (on an unpaired female) has been reported [Bruggers and William, 1981]. Average penis length of a second-year male Mandarin is $5.3 \mathrm{~cm}$, and its diameter is $3-4 \mathrm{~mm}$. The penis has some black coloration on the outer surface of its ridges [Brennan, unpubl. data]. Laysan ducks (Anas laysanensis), by contrast, are also socially monogamous, but males vigorously pursue FEPCs, sometimes killing the female in the process [Moulton and Weller, 1984; Brennan, unpubl. data]. Laysan ducks form seasonal pair bonds in fall and winter that break after the female begins nesting in the spring. Males do not assist with the brood rearing [Moulton and Weller, 1984]. Average penis length of a second-year male is $8.5 \mathrm{~cm}$, and its diameter is $9-10 \mathrm{~mm}$. The penis has multiple ridges along its surface and lacks external coloration [Brennan, unpubl. data]. These 2 species were compared to the Pekin duck (Anas platyrhynchos domesticus), our reference model species for which select stages of penis development were described previously [Herrera et al., 2013]. Pekin duck external genital morphology is similar to that of the Laysan duck [Brennan, pers. obs.] (fig. 1J-L). Pekin ducks are derived from wild mallards (Anas platyrhynchos), that have high levels of FEPCs and long penises (8$10 \mathrm{~cm}$ ) [Coker et al., 2002; Brennan et al., 2007]. Given that divergent development at embryonic stages has been shown to underlie interspecific macroevolutionary differences in bird external genital morphology [Herrera et al., 2013], here we test the hypothesis that interspecific microevolutionary differences in duck penis morphology arise during the same developmental period.

In addition to describing potential differences in penis development between species of duck embryos, we also examined sexual differentiation of external genitalia. Female birds, like female mammals, are known to possess a structure homologous to the phallus [King, 1981]. Little is known about its anatomy, and in ducks it simply has been described as 'weakly developed' [King, 1981]. The mechanisms underlying sexual differentiation of the male and female phallus in birds are poorly understood. In mammals and birds, the male penis and female clitoris are derived from the same embryonic structure, the genital tubercle [Wolff and Wolff, 1951; Cohn, 2011; Herrera et al., 2013]. At early stages of development, the external genital structures (genital tubercle, genital folds, and genital swellings) are sexually undifferentiated; however, a second phase of development, under the control of sex steroids (i.e. androgens and estrogen), directs the genital tubercle along sexual differentiation pathways that result in formation of the penis and scrotum in males and the clitoris and labia in females [Wolff and Wolff, 1951; Blaschko et al., 2012].

We recently compared penis development in anseriforms (waterfowl, including ducks, geese, swans, and allies), which have elongated intromittent penises, and galliforms (land fowl, including chickens, quails, turkeys, and allies), which have reduced, non-intromittent phallic swellings [King et al., 1981], and identified a developmental mechanism involved in the evolutionary transition from intromittent to non-intromittent penis [Herrera et al., 2013]. In chicken (Gallus gallus) embryos, the penis becomes non-intromittent as a result of apoptosis of the cells at the tip of the genital tubercle leading to regression of the phallus in the embryo, and we showed that this mechanism evolved de novo in male galliforms, rather than being lost in male anseriforms [Herrera et al., 2013]. These findings raised the possibility that the same or a similar mechanism underlies reduction of the female anseriform phallus during sexual differentiation, and here we also evaluate this hypothesis.

\section{Methods}

\section{Embryo Collection}

Fertilized chick (White Leghorn) eggs were obtained from Charles River Laboratories (Conn., USA). Laysan and Mandarin duck eggs were obtained during an experiment conducted at the Livingstone Ripley Waterfowl Conservancy (Yale University IACUC permit 2008-10906). Eggs were collected every other day and kept at $4{ }^{\circ} \mathrm{C}$ for up to 2 weeks prior to incubation. Pekin duck eggs were obtained commercially. Chick and duck eggs were incubated in a humidified incubator at $38^{\circ} \mathrm{C}$. Staging was standardized using the Hamburger-Hamilton $(\mathrm{HH})$ staging guide [Hamburger and Hamilton, 1951]. Embryos were sexed genotypically by PCR with sex-specific primers [Itoh et al., 2001].

\section{Histology/Morphology}

Embryos collected for morphology were genotyped for sex and then fixed in either $4 \%$ paraformaldehyde or Bouin's fixative (Sig- 
Pekin

Males

Early

(st. 27-29)
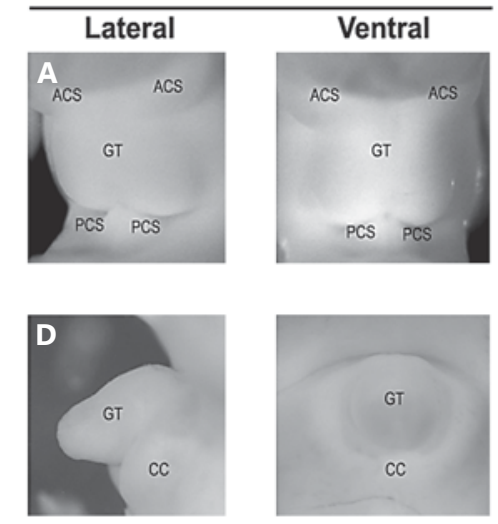

Mid

(st. 35-36)
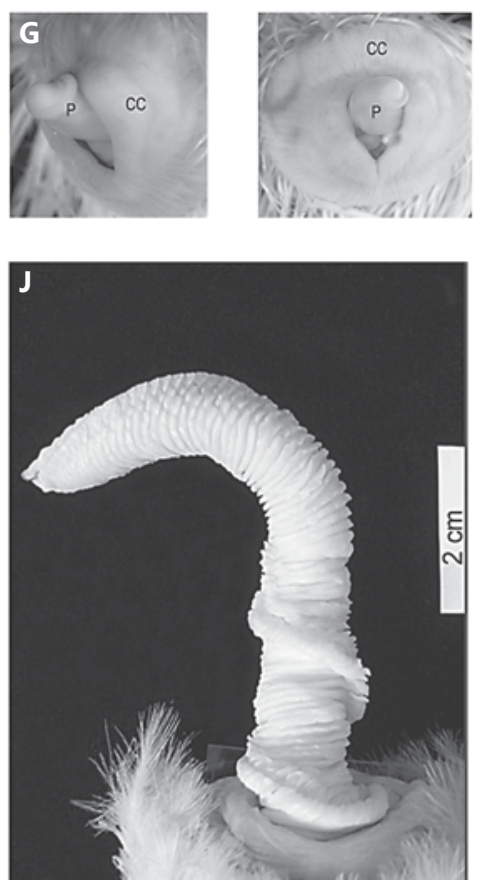
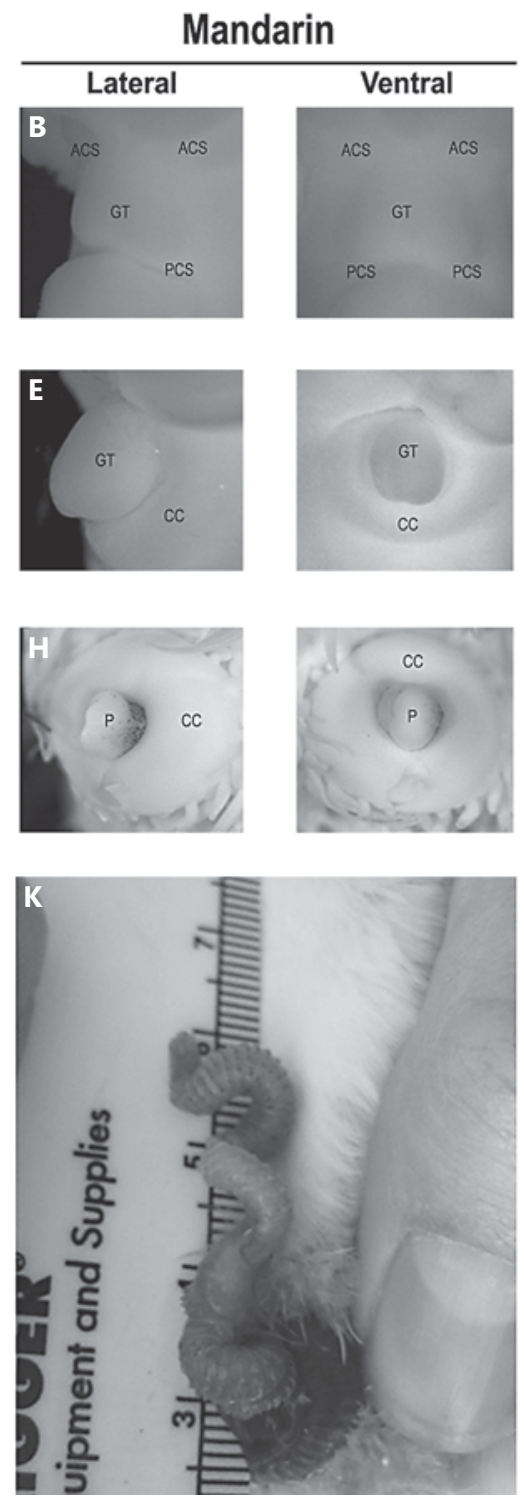
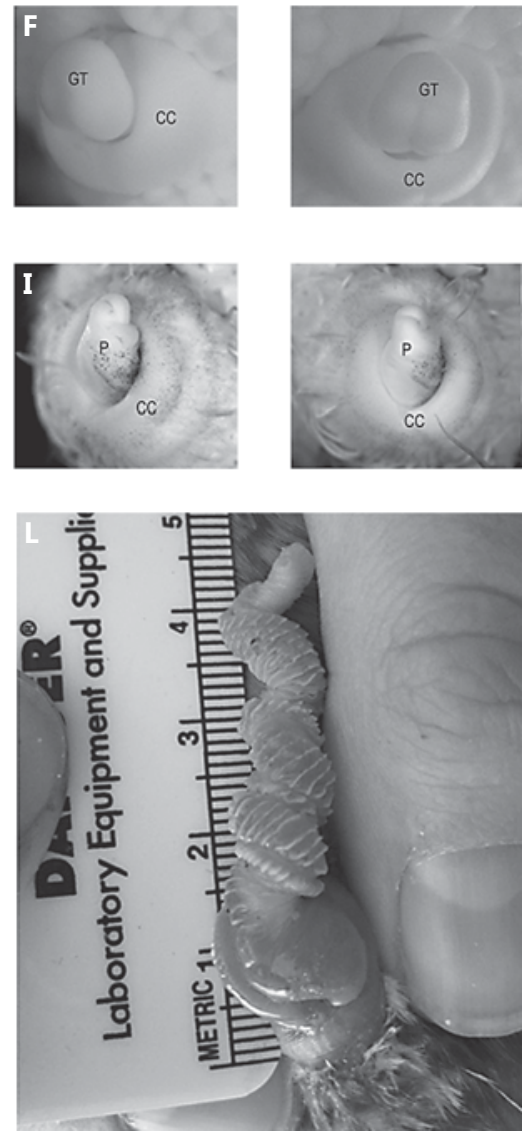

Fig. 1. A-I Comparison of male external genital morphogenesis at early (st. 27-29; A-C), mid (st. 35-36; D-F) and late (st. 40-44; G-I) stages of embryonic development in Pekin, Mandarin and Laysan ducks. Lateral and ventral views of external genitalia are shown. Note that morphological patterning of male genitalia is similar across these 3 species throughout the stages of pre-hatch development. J-L Everted penises of adult male Pekin (J), Mandarin (K) and Laysan ducks (L). ACS = Anterior cloacal swelling; $\mathrm{CC}=$ cloacal collar; $\mathrm{GT}=$ genital tubercle; $\mathrm{P}=$ phallus; $\mathrm{PCS}=$ posterior cloacal swelling. ma, HT10132). Embryos were imaged in whole mount using light microscopy and then processed overnight through an ethanol series, xylene, and a 1:1 mixture of paraplast plus (Fisher, 23-021400) and paraplast $\mathrm{x}$-tra (McCormick, 39503002) using a Leica TP1020 tissue processor. Samples were then embedded, sectioned $(8 \mu \mathrm{m})$ and slides were stained using Masson Trichrome Chromaview Stain Kits (Richard-Allan Scientific) following the manufacturer's instructions.

Interspecific Development and Sexual Differentiation of Bird Genitalia

\section{Results}

Comparative Development of External Genitalia in

Pekin, Laysan and Mandarin Ducks

In order to determine whether differences in phallus morphology among Pekin, Mandarin and Laysan ducks (fig. 1J-L) arise during embryonic development, we examined external genital development in a staged series of 
Table 1. Morphological features of duck external genital development before sexual differentiation

HH stage Key morphological features

Schematic

26 Emergence of 3 paired swellings. Anterior cloacal, genital and posterior cloacal swellings emerge in between limb buds, tail and gut.

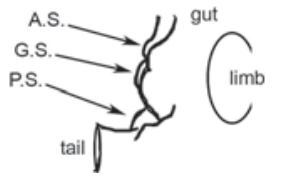

27/28 Anterior cloacal and genital swellings fuse to form the genital eminence. Formation of the midline. Posterior cloacal swellings extend further from the tail bud.

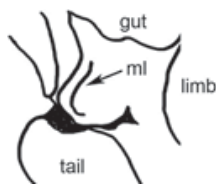

29 Genital tubercle forms from genital eminence. The sulcus forms ventral to the genital tubercle. Posterior cloacal swellings merge towards the ventral midline of the genital tubercle.

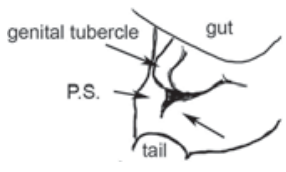

30 Genital tubercle begins to elevate off of body wall. Continual outgrowth of the genital tubercle and fusion of the posterior cloacal swellings create a cavity ventral to the genital tubercle.

32 Anterior and posterior cloacal swellings fuse to form the genital/cloacal collar. Anterior and posterior cloacal swellings surround the genital tubercle to form the genital/cloacal collar.
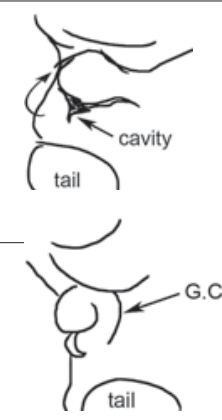

$34 \quad$ Sulcus opening is visible on the ventral side of the genital tubercle. The seam of the urethral plate begins to develop small openings.

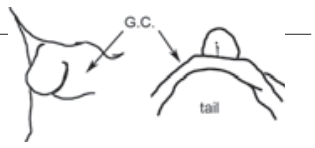

35 Genital tubercle continues to grow out; feather buds emerge around the cloacal collar. A ridge can be seen on the dorsal midline of the genital tubercle.

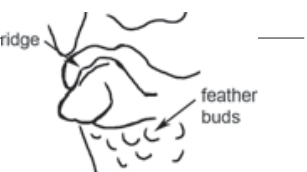

36 Genital tubercle extends dorsally. The tubercle bends dorsally just before the onset of coiling.

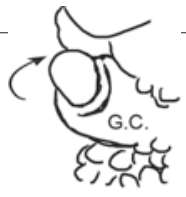

38 Pigmentation of the genital tubercle and feathers. Melanocytes can be seen at the base of the genital tubercle as well as at the distal ends of the feathers.

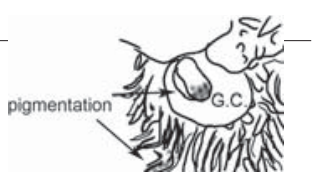

A.S. = Anterior cloacal swelling; G.C. = genital/cloacal collar; G.S. = genital swelling; $\mathrm{ml}=$ midline; P.S. = posterior cloacal swelling. 


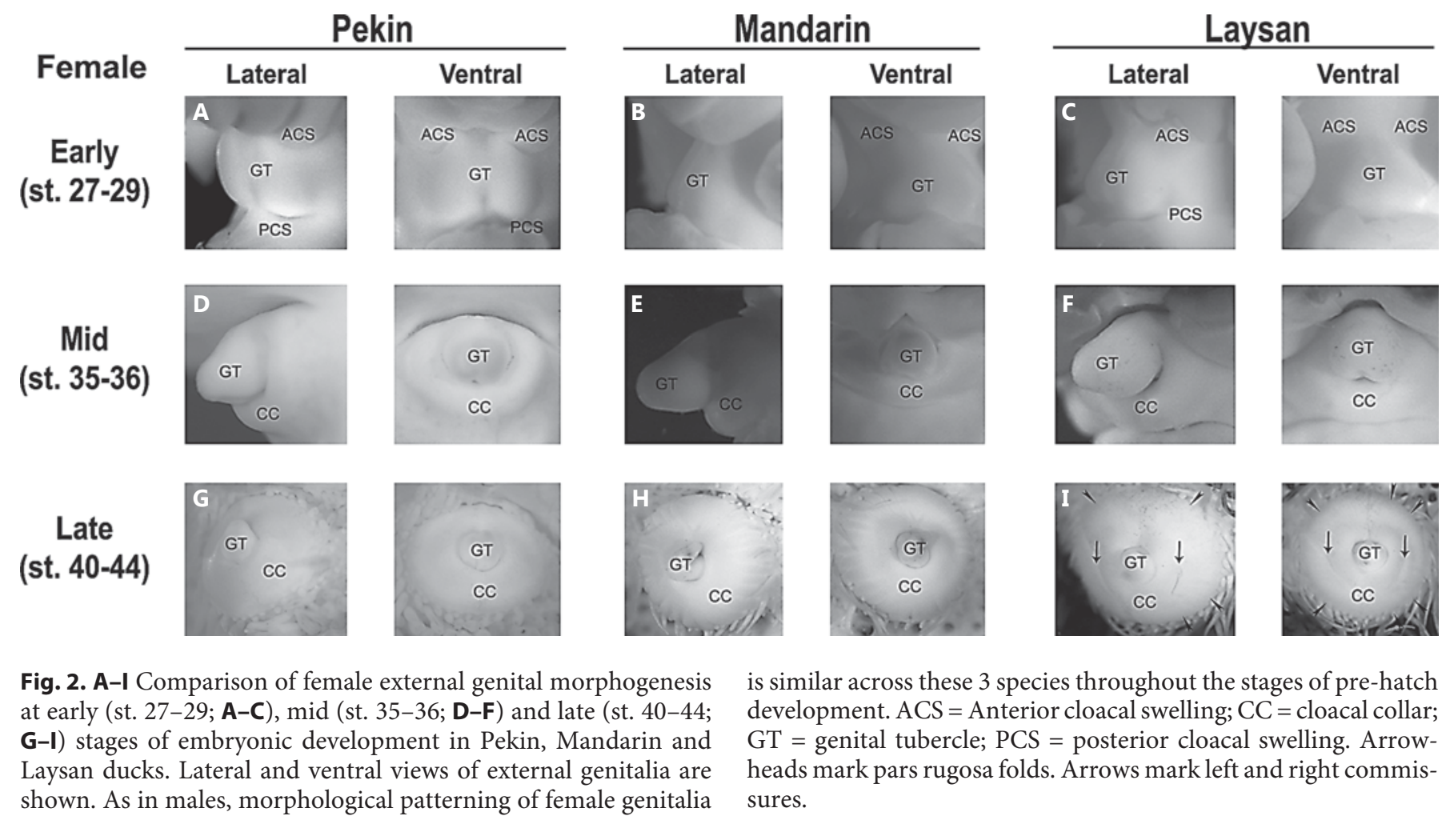

male and female embryos from all 3 species. Initiation of the external genitalia begins at stage 26 in males and females of each species and, by stage 27, 3 pairs of swellings have emerged on each side of the cloacal membrane (the bilaminar epithelial plate that forms where the posteriormost endoderm of the hindgut contacts the surface ectoderm of the proctodeum; note that this region also has been referred to as the anal plate or cloacal plate) [Romanoff, 1960; Bodemer and Barth, 1968; Patten and Carlson, 1974; Bakst, 1986]. A complete developmental series is provided for both sexes and all 3 species in online supplementary figures 1-3 (for all online suppl. material, see www.karger.com/doi/10.1159/000364927; see also table 1). The 3 pairs of swellings, known as the anterior cloacal, genital and posterior cloacal swellings, give rise to different structures around the cloaca. The genital swellings, situated between the anterior and posterior cloacal swellings, fuse to form a single genital tubercle (figs. 1A-C, $2 \mathrm{~A}-\mathrm{C})$. The anterior swellings fuse to form the anterior (cranial) portion of the cloacal collar, and the posterior swellings fuse to form the posterior (caudal) aspect of the cloacal collar (table 1; online suppl. figs. 1B, B', K, K', 2C, C', H, H', 3B, B', L-L'). At these stages, we observed no morphological differences between sexes within any of

the 3 species, nor were there any overt differences between members of the same sex across these species.

As the genital tubercle grows and extends distally, the anterior and posterior lips of the cloacal collar continue to grow and surround the tubercle. The anterior and posterior sides of the collar join together by stage 34 to form the circumferential cloacal collar, which surrounds the genital tubercle and cloacal outlet. The sulcus spermaticus, through which sperm are ejaculated, becomes visible as an external groove on the ventral side of the genital tubercle (table 1; online suppl. figs. 1C, D", L", 2D"-F", I"-K", 3C"-F", L"-O"). The embryonic phallus remains associated with the anterior wall of the cloacal collar as it grows distally and extends dorsally (figs. 1D-F, 2D-F). By stage 38 , pigmented melanocytes have accumulated around the base of the genital tubercle and in the surrounding feather buds in birds with colored plumage (Laysan and Mandarin) (table 1; online suppl. figs. 2G, L-N, 3E-I, P).

\section{Sexual Differentiation of External Genitalia in Ducks}

Male and female duck genital tubercles and cloacal collars develop similarly from the initiation of budding until stage 40 in each of the 3 species examined here (ta- 
HH 36

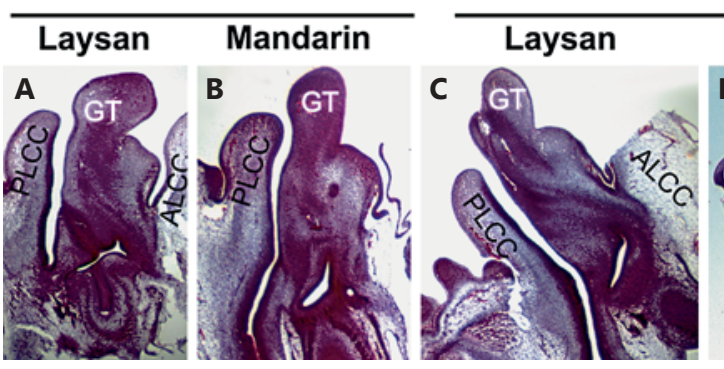

HH 37

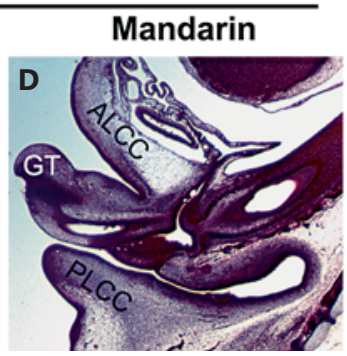

HH 40

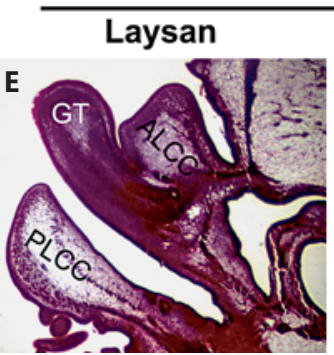

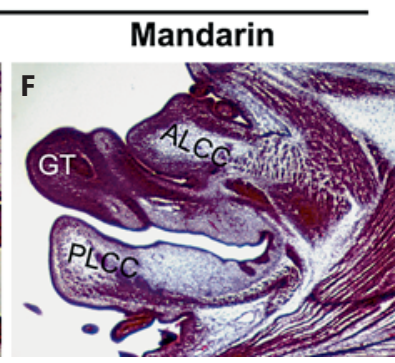

Fig. 3. Histological sagittal sections of the phallus of Laysan and Mandarin duck embryos at HH stages 36 (A, B), 37 (C, D) and 40 (E, F). ALCC = Anterior lip of cloacal collar; GT = genital tubercle; PLCC = posterior lip of cloacal collar.

Table 2. Morphological features of duck external genital development during sexual differentiation

\begin{tabular}{ll}
\hline HH stage & Key morphological features \\
\hline 40 & $\begin{array}{l}\text { Reduction/broadening of genital tubercle. In females, a } \\
\text { massive reduction in genital tubercle size begins. In males, } \\
\text { the genital tubercle becomes rounder and broadens. Both } \\
\text { sexes show a turn of the genital tubercle for initiation of } \\
\text { clockwise twisting. Both sexes show pars rugosa folds that } \\
\text { surround the genital/cloacal collar radially. }\end{array}$
\end{tabular}

$41 \quad$ Pars plana can be distinguished. The pars rugosa continues to become more pronounced, while in females the beginnings of the left and right commissure indentations into the collar can be seen. In both sexes, the pars plana fold starts to show.
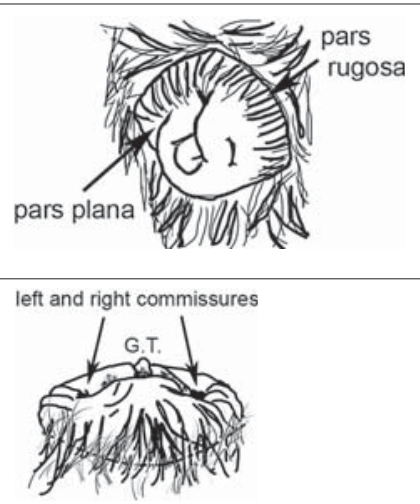

pars plana

42 Complete reduction/extended outgrowth. In females, the left and right commissures have folded inwards creating a distinct dorsal and ventral lip from the genital/cloacal collar. The genital tubercle is completely reduced to a small structure that sits on the ventral wall of the cloaca. Conversely, in males, the tubercle continues to grow distally with a dorsal bend.

43-45 Genital/cloacal collar envelops genital tubercle; genital tubercle continues to turn. In females, the genital/cloacal collar exhibits radial folds from the pars rugosa, the left and right commissures and the pars plana. The reduced genital tubercle is hidden behind the dorsal and ventral lips as they thicken. In males, the genital tubercle twists counterclockwise as the tubercle extends distally. The general pattern for both sexes is established and undergoes minimal change until hatching.
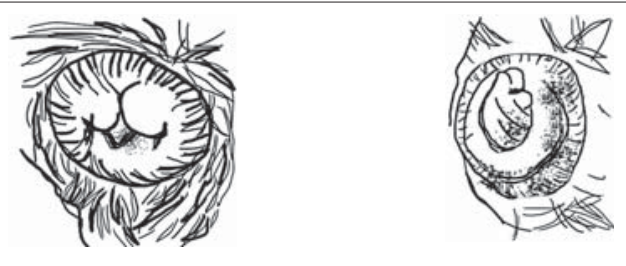

G.T. $=$ Genital tubercle. 
ble 1; online suppl. figs. 1-3). Sagittal sections through the cloaca show that the anterior cloacal swelling is contiguous with the proximal region of the genital tubercle, but the posterior cloacal swelling emerges as a separate outgrowth on the posterior/dorsal side of the cloaca (fig. 3AF). From stage 40, the female genital tubercles of Pekin, Mandarin and Laysan ducks begin to regress (fig. 2G-I; table 2), but the male genital tubercles continue to grow out, broaden dorsoventrally and coil (fig. 1G-I; table 2). In females, the genital tubercle regresses towards the tip of the cloacal collar, although it remains well differentiated with a pronounced epithelial sulcus (fig. 2G-I; table 2).

Like the genital tubercle, the cloacal collar undergoes distal outgrowth and circumferential expansion from the time that the anterior and posterior lips fuse (figs. 1D-I, 2D-I). Cloacal collar development occurs both in males and females; however, as a result of the reduction of the phallus in females, the cloacal collar extends beyond the distal tip of the phallus, and eventually envelops the female phallus (fig. 2G-I; table 2).

A major transformation occurs in female external genitalia between stages 40 and 41 ; there is a marked reduction in the proximodistal length and dorsoventral width of the female tubercle (figs. 2G-I; online suppl. figs. 1EF", 3G-G"). A spherical mass of cells aggregates at the distal tip of the female tubercle, suggesting that regression might involve apoptosis (online suppl. fig. 4). In males, however, the phallus continues to elongate, broaden and coil counter-clockwise, causing the sulcus spermaticus to twist radially down the length of the phallus (fig. 1G-I; online suppl. figs. 1P-Q", 2L-N", 3P-P"). In both sexes, the proximal tubercle remains attached to the base of the anterior lip of the cloacal collar (fig. 3E, F). By stage 43, the female phallus has regressed further into the cloacal collar, whereas in males, the penis continues to broaden and coil, with each turn becoming more prominent and complex (compare figs. 1G-I and 2G-I; table 2). Interestingly, clockwise coiling of the phallus is initiated in males and females. During this period, the cloacal collar begins to make the pars rugosa (folds that circumscribe the lateral part of the cloacal collar) and pars plana folds (folds invaginate into the medial part of the cloacal collar; table 2; figs. 1I, 2I) [Bakst and Cecil, 1986]. By stage 42, the female phallus is barely visible beyond the cloacal collar (fig. 2G-I). Once the female phallus has receded within the cloacal collar, clefts known as the cloacal commissures form on the left and right sides of the cloacal collar, between the anterior and posterior halves, separating the prospective anterior and posterior cloacal lips. This divi-

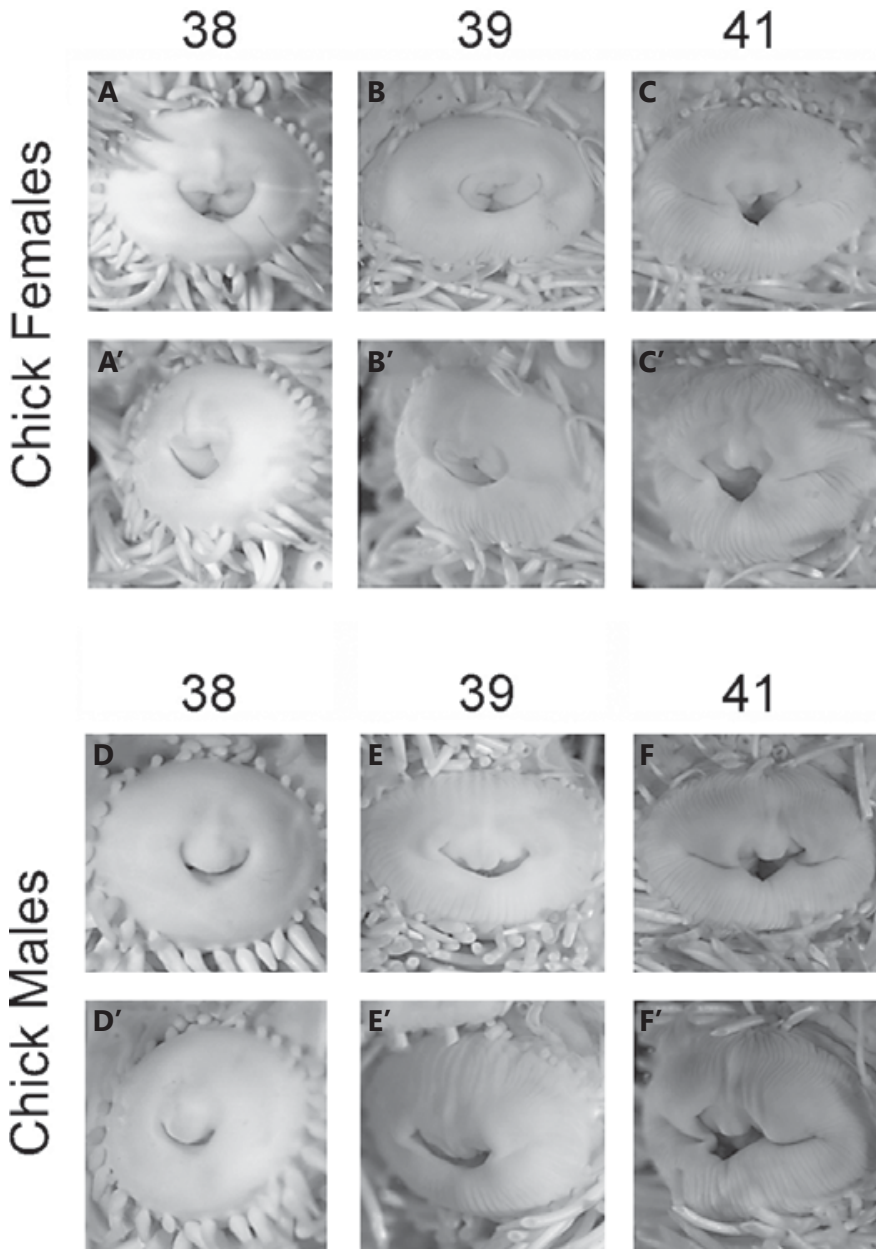

Fig. 4. Comparative development of female and male chick genitalia at late stages $(38,39$ and 41$)$ of sexual differentiation. A$\mathbf{C}^{\prime}$ Ventral $(\mathbf{A}-\mathbf{C})$ and lateral $\left(\mathbf{A}^{\prime}-\mathbf{C}^{\prime}\right)$ views of female chick genitalia. D-F' Ventral (D-F) and lateral ( $\left.\mathbf{D}^{\prime}-\mathbf{F}^{\prime}\right)$ views of male chick genitalia.

sion does not occur in male genital tubercles; rather, the pars plana folds surround the prospective phallus (fig. 1I; table 2; online suppl. figs. 1F-I", O-Q", 3H-I").

\section{Regression of the Non-Intromittent Phallus in Male} Chicks Resembles Sexual Differentiation of the Female Phallus in Ducks

Sexual differentiation of the non-intromittent phallus of male chickens is markedly different to the intromittent phallus of male ducks. In male chick embryos, the phallus regresses within the cloacal collar and is covered by the dorsal and ventral lips (fig. 4), which closely resembles the late stage of phallus differentiation in female ducks. A similar regressive process has been described during de- 
velopment of the male genitalia in other galliforms such as turkeys [Bakst and Cecil, 1986]. We reported previously that the outgrowth of the chick genital tubercle arrests by stage 35 , and it has regressed by stage 45 [Herrera et al., 2013] (see also fig. 4). Our observation that sexual differentiation of female duck genitalia more closely resembles that of male chickens led us to examine the stages of chick genital differentiation that occur during the process of phallus regression. Between stages 38 and 41 , the anterior and posterior lips of the chick cloacal collar continue to grow in both male and female embryos (fig. 4). At stage 38, the male and female phalluses appear as rudimentary buds that extend from the anterior lip of the cloaca across the cloacal opening (fig. 4A, A', D, D'). By stage 39, the female phallus has undergone further regression and curves back towards the inner wall of the cloacal collar (fig. 4B, B'). At the same stage, the male phallus appears regressed and curved inward (fig. 4E, E'). Over the next 2 stages, the cloacal lips grow and eventually envelop the phallus in both sexes (compare fig. 4A-C' with online suppl. fig. 1F-I", O-Q'). Thus, by stage 41, the phallus of male and female chicks is contained within the cloacal collar, whereas in ducks, only the female phallus is enveloped by the cloacal collar.

\section{Discussion}

Male genitalia are considered among the most variable morphological structures in animals that reproduce by internal fertilization [Eberhard, 1985] and, among vertebrates, birds are one of the most extreme examples of this morphological diversity. Studies of avian genitalia can provide important insights into the mechanisms of macro- and microevolution, such as the evolutionary reduction and loss of traits that are associated with reproductive success. Our results indicate that, despite the significant morphological differences in adult phallus morphologies of Laysan, Mandarin and Pekin ducks, development and growth at embryonic (pre-hatching) stages are highly conserved. This contrasts with the divergent pre-hatch development of chick and duck genitalia [Herrera et al., 2013]. The conserved development of genitalia across the duck species compared here suggests that their divergent phallus morphologies arise after hatching, perhaps reflecting differences in their responses to sex steroids during sexual maturation. By contrast, in each of these species, differentiation of the male and female phalluses occurs during embryonic stages, similar to the differences be- tween chicken and duck genitalia [Wolff and Wolff, 1951; Herrera et al., 2013].

\section{Interspecific Differences in Duck Phallus Morphology}

Although the differences in penis length among the species studied here do not encompass the full range of length variation found across waterfowl, variation in penis morphology is nevertheless easily distinguishable in adults, where the width and length of the penis in male Laysan and Pekin ducks are much greater than in Mandarin ducks. Despite this, we found no detectable differences in external genital development at early or late embryonic stages. Given the high degree of developmental conservation prior to hatching, the morphological differences seen in adult phalluses of these species likely arise post-hatch, and are controlled by sex steroids. Androgens and estrogens play major roles in the masculinization and feminization of genital and secondary sexual characters at prenatal, neonatal and postnatal stages in mammals. The effects of androgens and estrogens during development have been reported to occur in multiple waves that act on sexually dimorphic organ development during time-sensitive windows [Nussey and Whitehead, 2001]. In mammals, the third of these waves occurs during sexual maturation/puberty and is responsible for the differentiation of secondary sexual characters. This postnatal sexual maturation is known as adrenarche and is responsible for the postnatal sexual maturation in higher primates [Belgorosky et al., 2008; Conley et al., 2012]. Adrenarche is caused by secretion of adrenal androgens by the zona reticularis; however, the mechanisms that regulate this process are still poorly understood. In birds, seasonal changes that signal mating and testicular maturation also may act as virilization cues for elaboration of the phallus. The specific mechanism has not been elucidated, but phallus size is known to be influenced by testosterone in mallard males [Höhn, 1960]. Most ducks grow and elaborate the phallus during the mating season and regress most of the structure when the breeding season is over [Höhn, 1960; Brennan et al., unpubl. data]. Evidence that sex steroids can modulate social behaviors and mating practices [Goymann, 2009; Charlier et al., 2013] as well as genital form suggests that a common hormonal mechanism may link copulatory behavior with testicular and phallus morphology.

\section{Sexual Differentiation of Duck Phallus Morphology}

We found that reduction of the female phallus occurs fully within the pre-hatch period of duck development. Major patterning changes to the duck genital tubercle and 
cloacal collar occur at later stages of sexual differentiation, from stage 40 onward. At these stages in females, the genital tubercle undergoes severe reduction. Our observation of a mass of apoptotic cells at the tip of the female genital tubercle at these stages suggests that programmed cell death may play a role in regression of the female phallus. In males, the tubercle continues to grow and elaborate, becoming thicker, more pigmented and coiled. The cloacal collar in both males and females begins to form the radial folds of the pars rugosa and to establish the medial folds of the pars plana. In females, the pars plana along with the left and right commissures, create a division of the anterior and posterior lips of the cloaca. In males, this division does not occur and the pars plana continues to extend around the cloacal collar that surrounds the genital tubercle. During later stages of genital development, from stage 43 to hatching, these sex-specific characteristics become increasingly pronounced in duck genitalia. Upon hatching, male ducklings have a well-differentiated and easily distinguishable phallus, whereas female ducklings do not. This contrasts sharply with sexual differentiation of the external genitalia in chicks. Indeed, determining the sex of chick hatchlings is difficult due to the similarities between male and female genitalia.

External genital development in male chicks, which have non-intromittent phalluses, closely resembles that of female ducks. We reported previously that the pattern of apoptosis induced by BMP signaling, which results in a non-intromittent penis in chicks, likely evolved de novo in male galliforms [Herrera et al., 2013]. The results presented here raise the possibility that arrest and regression of the phallus in male galliforms may involve the same mechanism, albeit at an earlier stage, that drives phallus regression in female anseriforms. As such, the non-intromittent phalluses of male galliforms may reflect feminization or undervirilization. A comparative molecular study of late-stage sexual differentiation in birds will be required to determine the extent to which the underlying mechanisms are conserved.

\section{Acknowledgements}

We thank Ian Gereg and the Livingstone Ripley Waterfowl Conservancy for their assistance with Laysan and Mandarin egg collection, members of our laboratories for comments on earlier drafts of the manuscript, and Emily Merton for assistance with figures. We acknowledge support from the National Science Foundation (grant numbers IOS-0843590 to M.J.C. and IOS-0920344 to P.L.R.B.), the National Institute of Environmental Health Sciences (R01-ES017099 to M.J.C.) and the Howard Hughes Medical Institute (to M.J.C.). Any opinions, findings, conclusions, or recommendations expressed in this material are those of the authors and do not necessarily reflect the views of the National Science Foundation.

\section{References}

Afton A: Forced copulation as a reproductive Brennan PLR, Prum RO: The limits of sexual constrategy of male lesser scaup: a field test of some predictions. Behaviour 92:146-167 (1985).

Bakst MR: Embryonic development of the chicken external cloaca and phallus. Scan Electron Microsc Pt2:653-659 (1986).

Bakst MR, Cecil HC: Embryonic development of the turkey male genitalia. Poultry Sci 65: 1623-1630 (1986).

-Belgorosky A, Baquedano MS, Guercio G, Rivarola MA: Adrenarche: postnatal adrenal zonation and hormonal and metabolic regulation. Horm Res 70:257-267 (2008).

-Blaschko SD, Cunha GR, Baskin LS: Molecular mechanisms of external genitalia development. Differentiation 84:261-268 (2012).

Bodemer CW, Barth LG: Modern Embryology (Holt, Rinehart and Winston Inc, New York 1968).

Brennan PLR: Genital evolution: cock-a-doodledon't. Curr Biol 23:R523-R525 (2013). flict in the narrow sense: new insights from waterfowl biology. Philos Trans R Soc Lond B Biol Sci 367:2324-2338 (2012).

Brennan PLR, Prum RO, McCracken KG, Sorenson MD, Wilson RE, Birkhead TR: Coevolution of male and female genital morphology in waterfowl. PLoS One 2:e418 (2007).

Brennan PLR, Birkhead TR, Zyskowski K, Van Der Waag J, Prum RO: Independent evolutionary reductions of the phallus in basal birds. J Avian Biol 39:487-492 (2008).

Briskie JV, Montgomerie R: Sexual selection and the intromittent organ of birds. J Avian Biol 28:73-86 (1997).

Bruggers R, William JB: Age-related differences in reproductive behaviour of male Mandarin ducks. Bird Study 28:107-114 (1981).

-Charlier TD, Seredynski AL, Niessen NA, Balthazart J: Modulation of testosterone-dependent male sexual behavior and the associated neuroplasticity. Gen Comp Endocrinol 190:24-33 (2013).
Cohn MJ: Development of the external genitalia: conserved and divergent mechanisms of appendage patterning. Dev Dyn 240:1108-1115 (2011).

Coker CR, McKinney F, Hays H, Briggs SV, Kimberly M: Intromittent organ morphology and testis size in relation to mating system in waterfowl. Auk 119:403-413 (2002).

Conley AJ, Bernstein RM, Nguyen AD: Adrenarche in nonhuman primates: the evidence for it and the need to redefine it. J Endocrinol 214:121-131 (2012).

Davis E: Male reproductive tactics in the mallard, Anas platyrhynchos: social and hormonal mechanisms. Behav Ecol Sociobiol 52:224231 (2002).

Dilger WC, Johnsgard PA: Comments on 'species recognition' with special reference to the wood duck and the Mandarin duck. Wilson Bull 71:46-53 (1959).

Eberhard WG: Sexual Selection and Animal Genitalia (Harvard University Press, Cambridge 1985). 
Goymann W: Social modulation of androgens in male birds. Gen Comp Endocrinol 163:149157 (2009)

Hamburger V, Hamilton HL: A series of normal stages in the development of the chick embryo. J Morphol 88:49-92 (1951).

- Herrera AM, Shuster SG, Perriton CL, Cohn MJ: Developmental basis of phallus reduction during bird evolution. Curr Biol 23:10651074 (2013).

Höhn E: Seasonal changes in the Mallard's penis and their hormonal control. Proc Zool Soc Lond 134:547-555 (1960).
Itoh Y, Suzuki M, Ogawa A, Munechika I, Murata K, Mizuno S: Identification of the sex of a wide range of Carinatae birds by PCR using primer sets selected from chicken EE0.6 and its related sequences. J Hered 92:315-321 (2001).

King A: Phallus, in King A, McLelland J (eds): Form and Function in Birds, pp 107-148 (Academic Press, New York 1981).

McCracken KG, Wilson RE, McCracken PJ, Johnson KP: Are ducks impressed by drakes' display? Nature 413:128 (2001).

McKinney F, Evarts S: Sexual coercion in waterfowl and other birds, in Parker P, Tyler Burley N (eds): Avian Reproductive Tactics: Female and Male Perspectives, pp 163-195 (American Ornithologists' Union, Washington 1998).
McKinney F, Derrickson SR, Mineau P: Forced copulation in waterfowl. Behavior 86:250294 (1983).

Moulton DW, Weller MW: Biology and conservation of the Laysan duck (Anas laysanensis). Condor 86:105-117 (1984).

Nussey SS, Whitehead SA (eds): The gonad, in Endocrinology: An Integrated Approach, pp 217-279 (BIOS Scientific Publishers, Oxford 2001).

Patten BM, Carlson BM: Foundations of Embryology (McGraw-Hill, New York 1974).

Romanoff AL: The Avian Embryo: Structural and Functional Development (Macmillan, New York 1960)

Wolff E, Wolff E: The effects of castration on bird embryos. J Exp Zool 116:59-97 (1951). 